\title{
EDITORIAL
}

\section{MIGRACIÓN, FRONTERAS, ASENTAMIENTOS E INDÍGENAS}

\author{
MIGRATION, BORDERS, SETTLEMENTS AND INDIGENOUS PEOPLE
}

\author{
Alberto Díaz Araya* \\ Eugenio Sánchez Espinoza*
}

La presente edición de Diálogo Andino. Revista de Historia, Geografía y Cultura Andina continúa los senderos de la divulgación de publicaciones científicas en el ámbito de las Humanidades y las Ciencias Sociales. En este camino laborioso, con una multiplicidad de desafíos, nos ha permitido que Diálogo Andino se transforme en un espacio abierto para la difusión de los resultados de investigaciones desarrolladas en los diversos contextos culturales y realidades complejas desde y sobre Latinoamérica.

En el presente $\mathrm{N}^{\circ} 51$ nos permitimos refrendar lo anterior con la entrega de artículos que abordan campos de análisis que tienen que ver con migraciones, fronteras, asentamientos humanos e indígenas en tanto su condición de pobreza como sus creencias religiosas, con un acento en los países andinos.

Así, José Daniel Benclowicz presenta un trabajo acerca de los exiliados chilenos en la Patagonia argentina en la década de los ochenta del siglo XX. Específicamente, estudia los flujos migratorios que permitieron el surgimiento de barrios populares en San Carlos de Bariloche (Argentina), donde destaca el asentamiento 10 de Diciembre, en el que grupos de chilenos destacaron en su proceso organizativo y social.

Seguidamente, Mauricio Chamorro discute los resultados de una investigación de carácter etnográfico desarrollada en el municipio de Gualmatán, ubicado en la región sur andina de Colombia, específicamente en el departamento de Nariño. Se realiza un análisis de la institución del compadrazgo, que en este municipio subsisten algunas relaciones de reciprocidad y redistribución, las que se han transformado en una estrategia social para enfrentar los cambios generados por el mercado.
Un estudio etnográfico de los indígenas Kichwas del cantón Ambato (provincia de Tungurahua, Ecuador) desarrollado por Judith Pinos, pone en evidencia la diversidad de significados que otorga este pueblo originario a la pobreza. El artículo logra recuperar la voz de los sujetos y el imaginario que han construido en torno a esta condición socioeconómica desde un enfoque étnico.

Mauricio Lorca fija su atención en la provincia de Chañaral (Chile), caracterizada por su pasado vinculado a la actividad minera, estudiando que el vínculo de la provincia con su tradición minera se ha traducido en una configuración particular del territorio. En este contexto, el autor indaga la forma en que el pasado minero-industrial puede transformarse en un recurso que ayude a sus habitantes a proyectarse hacia el futuro.

Una investigación relativa a la frontera chilenoboliviana es problematizada por Sergio González Miranda junto con César Ross y Cristián Ovando, analizando críticamente el contexto histórico de la "cuestión del río Lauca", transformando su trabajo en un aporte a la historia regional y diplomática de Chile y Bolivia. Los autores establecen que las diplomacias de los países involucrados en el conflicto no fueron capaces de predecir las consecuencias y el impacto político del pleito, ni tampoco su grado de amplificación, tanto a nivel nacional como internacional, relevando un conflicto fronterizo focalizado que alcanza hoy una intensidad insospechada.

Por otra parte, Víctor Guerrero centra su trabajo en la comuna de Iquique, ubicada en el litoral del norte de Chile, ciudad que en las últimas décadas ha experimentado ciertas transformaciones, sometida

\footnotetext{
* Universidad de Tarapacá, Departamento de Ciencias Históricas y Geográficas. Arica, Chile. Correos electrónicos: albertodiaz@ uta.cl; esanchez@uta.cl
} 
a los influjos propios del fenómeno de la globalización económica y al crecimiento demográfico. De acuerdo con el autor, en este nuevo escenario ha permitido el surgimiento de un nuevo sujeto costero que se encuentra sometido a un conjunto de expectativas y tendencias culturales que han modificado notablemente su realidad social, materias que son discutidas por Guerrero.

Finalmente, publicamos un artículo de los investigadores Mansilla, Muñoz y Pinoñes, quienes exploran conceptualizaciones y datos etnográficos respecto de la visión de los migrantes evangélicos peruanos y bolivianos indígenas (aymaras y quechuas) concernientes al pentecostalismo chileno. Los autores investigan y comparan la forma del pentecostalismo nacional y el de los países de origen de los migrantes indígenas asentados en la ciudad de Arica e Iquique. Además, proponen el concepto de postpentecostalismo para abordar la crisis que vive el pentecostalismo actual en el norte de Chile. 